\title{
Suitability of carbon fiber-reinforced polyetheretherketone cages for use as anterior struts following corpectomy
}

\author{
Robert F. Heary, MD, ${ }^{1,2}$ Naresh K. Parvathreddy, BE, MS, ${ }^{1,2}$ Zainab S. Qayumi, MD,,2 \\ Naiim S. Ali, MD, ${ }^{1,2}$ and Nitin Agarwal, MD ${ }^{1-3}$ \\ ${ }^{1}$ Department of Neurological Surgery; ${ }^{2}$ Spine Biomechanics Laboratory, Rutgers New Jersey Medical School, Newark, New \\ Jersey; and ${ }^{3}$ Department of Neurological Surgery, University of Pittsburgh Medical Center, Pittsburgh, Pennsylvania
}

\begin{abstract}
OBJECTIVE Fibular allograft remains a widely used strut for corpectomy surgeries. The amount of graft material that can be packed into an allograft strut has not been quantified. Cages are an alternative to fibular allograft for fusion surgeries. The authors of this study assessed the suitability of carbon fiber-reinforced polyetheretherketone (CFRP) cages for anterior corpectomy surgeries. They further explored the parameters known to affect fusion rates in clinical practice.

METHODS Six fibular allografts were tested at standard lengths. Three sets of carbon fiber cages (Bengal, DePuy Spine), each with a different footprint size but the same lengths, were tested. The allografts and cages were wrapped in adhesive, fluid-tight transparent barriers and filled with oil. The volume and weight of the oil instilled as well as the implant footprints were measured. The fibular allografts and cages were tested at 20-, 40-, and 50-mm lengths. Two investigators independently performed all measurements 5 times. Five CFRP cubes $(1 \times 1 \times 1 \mathrm{~cm})$ were tested under pure compression, and load versus displacement curves were plotted to determine the modulus of elasticity.
\end{abstract}

RESULTS Significantly more oil fit in the CFRP cages than in the fibular allografts $(p<0.0001)$. The weight and volume of oil was 4-6 times greater in the cages. Interobserver $(r=0.991)$ and intraobserver $(r=0.993)$ reliability was excellent. The modulus of elasticity for CFRP was $16.44 \pm 2.07 \mathrm{GPa}$.

CONCLUSIONS Carbon fiber-reinforced polyetheretherketone cages can accommodate much more graft material than can fibular allografts. In clinical practice, the ability to deliver greater amounts of graft material following a corpectomy may improve fusion rates.

http://thejns.org/doi/abs/10.3171/2016.1.SPINE14291

KEY WORDS cage; fibular allograft; strut; corpectomy; technique

$\mathrm{T}$ RADITIONAL interbody fusion techniques have used either structural autograft or allograft material. $, 13,29,44$ Although allograft and autograft have shown good results, problems related to graft expulsion and migration, graft site morbidity, and pseudarthrosis have been reported. $6,7,18,24,25,30,31,33,38,40,49,50$ For autologous bone, the quality of harvested bone, especially in elderly patients, and pain at the donor site have been additional issues. ${ }^{19,24,27,31,36,40}$ Concerns related to allograft include poor osteoconductive and osteoinductive properties, increased risk of infection, possible disease transmission, and poor biocompatibility. ${ }^{24,25,27,36,40,49}$
In an attempt to overcome these problems with autografts and allografts, the use of interbody fusion cages has been advocated. Advantages of interbody cages include immediate anterior column support and biocompatibility. ${ }^{20,26,45}$ Interbody fusion cages have been developed using a wide range of biomaterials, including metals (most notably titanium), as well as carbon derivatives such as polyetheretherketone (PEEK) and carbon fiber polymers.

Typically, these cages are filled with autologous bone graft material to promote bony fusion. ${ }^{1,3}$ Historically, greater initial graft volumes have been purported to lead to a higher percentage of fusion successes..$^{22,41,52}$ Another fac-

ABBREVIATIONS CFRP = carbon fiber-reinforced polyetheretherketone; $\mathrm{PEEK}=$ polyetheretherketone.

SUBMITTED March 17, 2014. ACCEPTED January 21, 2016.

INCLUDE WHEN CITING Published online April 8, 2016; DOI: 10.3171/2016.1.SPINE14291. 
tor known to affect spinal fusion is the surface area available for fusion. A larger surface area has been attributed to improving the final mechanical result of the procedure. ${ }^{22}$ Therefore, the volume of graft material that can be packed into an anterior column construct as well as the surface area available for fusion may affect the rates of spinal fusion (Fig. 1). To our knowledge, no study has compared these factors among the different anterior column fusion constructs.

Therefore, we investigated a carbon fiber-reinforced PEEK (CFRP) cage for stabilizing and reconstituting the anterior spine. The perceived advantages of this cage include the ability to impart immediate stability to the spine, the opportunity to place a significant amount of bone graft material inside the cage, a modulus of elasticity similar to that of adjacent bone, and radiolucency.

Our aim in this study was to compare the amount of material that could be placed into a CFRP cage with a fibular allograft of similar lengths by performing both weight and fluid quantitative analysis. In addition, to confirm suitability as a strut material, the area of the footprint for each strut was determined, the load versus displacement characteristics of the CFRP cage (modulus of elasticity) were calculated, and the radiolucency of the CFRP cage was assessed.

\section{Methods}

A random sample of 6 human fibular allograft segments was procured from commercially available bone banks. Each segment was sectioned to a length of $50 \mathrm{~mm}$ using a sagittal saw to simulate a routine multilevel corpectomy procedure. One end of each graft was covered using an adhesive, fluid-tight transparent barrier (Tegaderm transparent dressing, 3M Health Care). The weight of each graft with its corresponding wrapping was measured using a Mettler Toledo AL54 analytical balance. Olive oil with a density of $0.899 \pm 0.015 \mathrm{~g} / \mathrm{ml}$ was instilled into each allograft strut using a syringe, and the volume of oil was recorded. The weight of each graft with both the wrapping and the oil was again measured. The weight of the oil instilled was measured by taking the difference between the weight of the graft with the wrapping and the oil, and the weight of the graft with the wrapping alone. The above procedure was repeated 5 times. Two investigators individually repeated these 5 measurements at separate time points to allow for the assessment of interobserver and intraobserver variability.

The grafts were then sectioned to 40-mm segments, rewrapped, weighed, instilled with oil, and reweighed as previously described. The grafts were then sectioned to

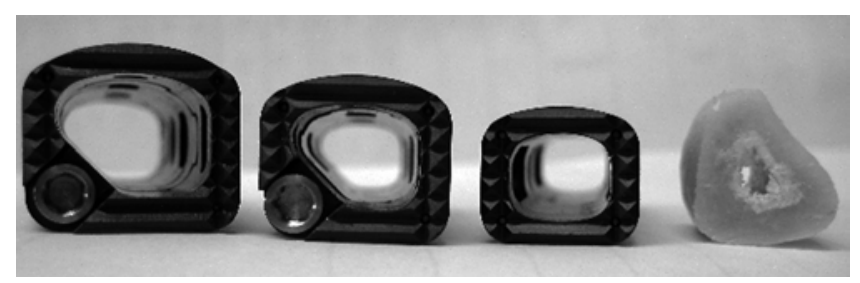

FIG. 1. Relative areas of fibular allograft (far right) and 3 different sizes of CFRP cages (far left to right: $16 \times 18 \mathrm{~mm}, 14 \times 16 \mathrm{~mm}, 12 \times 14 \mathrm{~mm}$ ). 20-mm segments (Fig. 2 left), and the weighing procedure was repeated with the same protocol. For each length, 2 separate investigators repeated the 5 measurements at separate time points.

The surface area of the internal and external footprint of each allograft was measured for each end of the strut. The internal and external circumference of each end of the allograft was first traced. Next, the area enclosed by the circumference was determined using a standard graphic Minkowski-Bouligand dimensioning technique.

Three sets of CFRP cages (Bengal, DePuy Spine) with a footprint size of $12 \times 14 \mathrm{~mm}$ and lengths of 20,40 , and $50 \mathrm{~mm}$ were obtained. The internal and external footprint of each cage was traced. For each footprint, internal and external footprint areas were calculated according to the protocol previously described for the allograft struts (these measurements confirmed the specifications provided by the manufacturer). One end and all 4 sides of each cage were wrapped with the adhesive, fluid-tight transparent barrier to ensure no fluid would leak from the construct. Each $12 \times 14-\mathrm{mm}$ cage was wrapped (Fig. 2 right), weighed, instilled with oil, and reweighed a total of 5 times. Two separate investigators repeated all 5 measurements on separate occasions.

The same process was performed for cages with footprint sizes of $14 \times 16 \mathrm{~mm}$ and $16 \times 18 \mathrm{~mm}$ at the 50-, 40-, and $20-\mathrm{mm}$ construct lengths. Statistical analyses were performed using SAS System for Windows 9.0 (SAS Institute Inc.).

Five CFRP (70\% PEEK + 30\% carbon) cubes $(1 \times 1 \times 1$ $\mathrm{cm})$ were obtained from the manufacturer. A pure compressive load was applied at the rate of $1 \mathrm{~mm} / \mathrm{min}$ using a mechanical fatigue-testing instrument (Instron 8821S, Instron Corp.). Load versus displacement curves were plotted in real time. Young's modulus of elasticity was calculated using the slope of the load versus displacement curves.

\section{Interobserver Reliability}

Interobserver reliability was assessed to determine any differences in the measurements made by the separate investigators. The weight and volume of olive oil used to fill the device and the size of the footprints of each strut (allograft and CFRP) were evaluated. Interobserver reliability was computed using the formula for the Pearson product-moment correlation coefficient:

$$
r_{x y}=\frac{\sum x_{i} y_{i}-n \overline{x y}}{(n-1) s_{x} s_{y}}=\frac{n \sum x_{i} y_{i}-\sum x_{i} \sum y_{i}}{\sqrt{n \sum x_{i}^{2}-\left(\sum x_{i}\right)^{2}} \sqrt{n \sum y_{i}^{2}-\left(\sum y_{i}\right)^{2}}}
$$

where $\overline{\mathrm{x}}$ and $\overline{\mathrm{y}}$ are the sample means of $\mathrm{x}$, which represents Investigator 1's measurements, and y, which represents Investigator 2's measurements, and where $\mathrm{s}_{\mathrm{x}}$ and $\mathrm{s}_{\mathrm{y}}$ are the sample standard deviations of $x$ and $y$ and the sum is from $i=1$ to $n .^{2}$

\section{Intraobserver Reliability}

Intraobserver reliability was assessed to determine the consistency of the measurements obtained from the same 


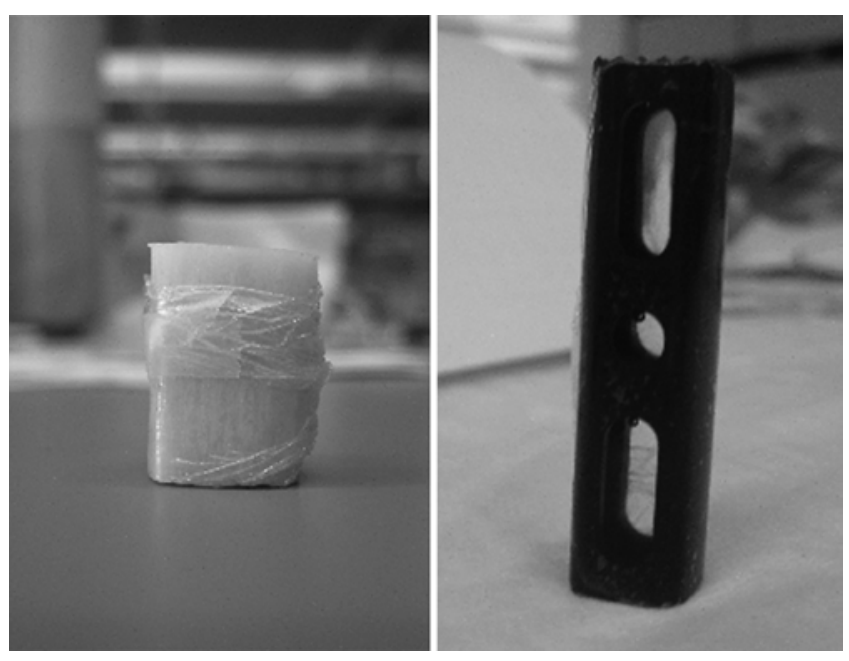

FIG. 2. Fibular graft wrapped with fluid-tight transparent barrier filled with olive oil (left) and CFRP cage wrapped with fluid-tight transparent barrier filled with olive oil (right).

experimenter at 5 different time points. Intraobserver reliability was also computed using the formula listed above. ${ }^{2}$ In addition, we obtained plain film radiographs and $\mathrm{CT}$ scans of cadaver spines into which CFRP cages were placed into a corpectomy defect at the T2 vertebral level to verify radiolucency. The cages were packed with morselized bone graft prior to implantation to simulate the clinical situation.

\section{Results}

All values represent the weight $(\mathrm{g})$ and volume $(\mathrm{ml})$ of the oil that could be instilled into the fibular allografts and CFRP cages so that the oil was flush to the top of the construct. All values were recorded as the mean \pm standard deviation (Table 1).

The average external and internal areas of the allograft footprints were compared with those of the cages for each of the 3 footprints. The external and internal cage footprints were significantly larger $(\mathrm{p}<0.0001)$ for all cage sizes than those for the allografts. The amount of olive oil in the 3 allograft lengths was compared with that in the equal-length cages of all 3 cage footprints. For all sizes of cages and allografts, the volume and weight of oil that fit into the cages was significantly greater than the volume and weight contained by the allograft struts $(\mathrm{p}<0.0001)$. Comparing both the weights and volumes of oil instilled, we found that the $12 \times 14-\mathrm{mm}$ cages could accommodate more than 4 times the amount of material, the $14 \times 16-\mathrm{mm}$ cages could accommodate more than 4.5 times the material, and the $16 \times 18-\mathrm{mm}$ cages could accommodate more than 6 times the material, compared with allografts of the same length (Figs. 3 and 4). The standard deviations of the volumes and weights of oil instilled were 5-10 times less for the cages, indicating the variability in sizes of the fibular allografts compared with sizes of the CFRP cages.

Interobserver reliability for volume measurements was 0.991 , and intraobserver reliability was 0.993 . Interobserver reliability for weight measurements was 0.987 , and intraobserver reliability was 0.990 . Interobserver reliability for area measurements was 0.986 , and intraobserver reliability was 0.982 . These values indicate extremely high precision and accuracy of data collection during the experiment both for different measurements by the same observer and between different observers.

Load versus displacement graphs were plotted for the CFRP cubes. The average Young's modulus of elasticity of the 5 CFRP cubes, calculated by measuring the slope of the load versus displacement curves, was $16.44 \pm 2.07$ GPa (Fig. 5).

\section{Discussion}

Traditional interbody fusion techniques have been used for over 40 years with good outcomes. Fusion rates for

TABLE 1. Comparison of weights and volumes of olive oil in allografts and 3 cages

\begin{tabular}{|c|c|c|c|c|c|}
\hline Measurement & Allograft & $12 \times 14-m m$ Cage & $14 \times 16-\mathrm{mm}$ Cage & $16 \times 18-m m$ Cage & $p$ Value* \\
\hline No. of cases & 6 & 3 & 3 & 3 & \\
\hline \multicolumn{6}{|l|}{$20 \mathrm{~mm}$} \\
\hline Weight (g) & $0.3306 \pm 0.14$ & $1.34 \pm 0.0087$ & $1.49 \pm 0.020$ & $2.04 \pm 0.07$ & $<0.0001$ \\
\hline Vol (ml) & $0.38 \pm 0.16$ & $1.51 \pm 0.012$ & $1.66 \pm 0.026$ & $2.24 \pm 0.023$ & $<0.0001$ \\
\hline Internal surface area $\left(\mathrm{mm}^{2}\right)$ & $22.48 \pm 1.13$ & $65 \pm 1.414$ & $57.6 \pm 0.57$ & $92 \pm 2$ & $<0.0001$ \\
\hline External surface area $\left(\mathrm{mm}^{2}\right)$ & $104.8 \pm 2.1$ & $165.6 \pm 0.57$ & $219.8 \pm 0.28$ & $2893 \pm 1.15$ & $<0.001$ \\
\hline \multicolumn{6}{|l|}{$40 \mathrm{~mm}$} \\
\hline Weight $(\mathrm{g})$ & $0.578 \pm 0.25$ & $2.69 \pm 0.033$ & $3.07 \pm 0.038$ & $4.33 \pm 0.038$ & $<0.0001$ \\
\hline Vol (ml) & $0.65 \pm 0.27$ & $3.01 \pm 0.017$ & $3.42 \pm 0.033$ & $5.15 \pm 0.06$ & $<0.0001$ \\
\hline Internal surface area $\left(\mathrm{mm}^{2}\right)$ & $21.22 \pm 0.55$ & $65 \pm 1.414$ & $57.6 \pm 0.57$ & $92 \pm 2$ & $<0.0001$ \\
\hline External surface area $\left(\mathrm{mm}^{2}\right)$ & $93.65 \pm 6.5$ & $165.6 \pm 0.57$ & $219.8 \pm 0.28$ & $2893 \pm 1.15$ & $<0.0001$ \\
\hline \multicolumn{6}{|l|}{$50 \mathrm{~mm}$} \\
\hline Weight $(\mathrm{g})$ & $0.71 \pm 0.26$ & $3.51 \pm 0.037$ & $3.93 \pm 0.065$ & $5.93 \pm 0.14$ & $<0.0001$ \\
\hline Vol (ml) & $0.80 \pm 0.30$ & $3.90 \pm 0.035$ & $4.41 \pm 0.063$ & $6.15 \pm 0.04$ & $<0.0001$ \\
\hline Internal surface area $\left(\mathrm{mm}^{2}\right)$ & $20.35 \pm 0.85$ & $65 \pm 1.414$ & $57.6 \pm 0.57$ & $92 \pm 2$ & $<0.0001$ \\
\hline External surface area $\left(\mathrm{mm}^{2}\right)$ & $90.16 \pm 0.83$ & $165.6 \pm 0.57$ & $219.8 \pm 0.28$ & $2893 \pm 1.15$ & $<0.0001$ \\
\hline
\end{tabular}

* $p$ values for all 3 cage footprints compared individually to allograft of the same length. 


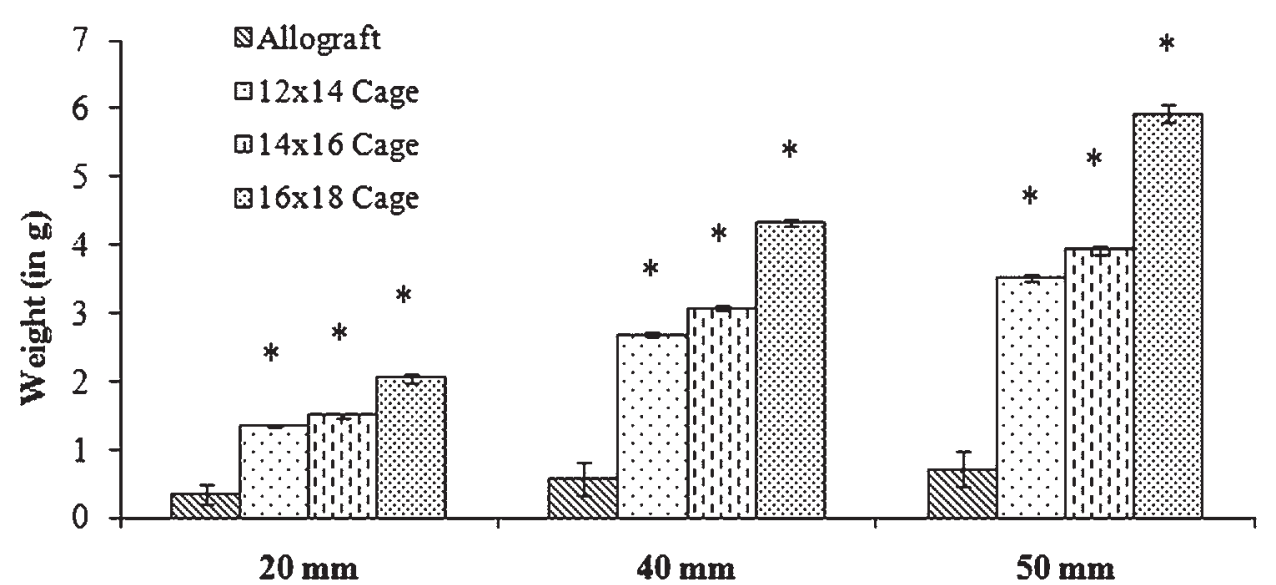

FIG. 3. Comparison of weight of olive oil that can be placed into 6 fibular allografts and 3 CFRP cages with different footprints. Asterisk indicates significant difference $(p<0.01)$, compared with allograft. $p<0.0001$ for each of the 3 sizes of cages.

single-level anterior discectomy and fusion are between $83 \%$ and $99 \%$ for structural autograft and between $82 \%$ and $94 \%$ for structural allograft. ${ }^{5,10,35,53}$ Fusion rates are appreciably lower for multilevel anterior surgeries than for single-level fusion surgeries. ${ }^{7,42}$ Iliac crest is the most common site for harvesting structural autograft because of convenient surgical accessibility and the quantity of available bone. Issues related to autologous iliac crest bone graft harvest are predominantly related to donor site morbidity. ${ }^{19,24,26,31,33}$ The disadvantages of using autograft bone include increased surgery time, increased blood loss, donor site infection, and donor site pain..$^{19}$ In addition, the quality of iliac crest bone in elderly patients is not always optimal. ${ }^{36}$ Concerns with allograft utilization include poor osteoconductive and osteoinductive properties, increased risk of infection, possible disease transmission, and biocompatibility. . $^{24,25,27,36,40,49}$ Complications with pseudarthrosis have been observed with both autograft and allograft fusions. ${ }^{6,18,50}$

In attempts to overcome the problems with bony strut grafts, interbody fusion cages have been developed. These cages can be made of metal, such as titanium or stainless steel, carbon fiber, or PEEK materials. Most often, the cages are filled with autograft material that can be obtained from the corpectomy procedure. The advantages of cages include elimination of donor site morbidity, immediate anterior column support, and uniform size or footprint of the anterior column support.

Several factors must be considered when evaluating the various interbody struts such as autograft and allograft bone grafts and cages made of titanium, steel, PEEK, or carbon fiber. These factors include radiolucency, mechanical properties, and device geometry. Radiolucency is an important factor when considering fusion constructs in order to noninvasively evaluate the progress of fusion. Conventional radiographs, CT scans, and MR images can be used to assess the presence of fusion postoperatively (Figs. 6 and 7). In the case of conventional radiographs, while noninvasive evaluation of fusion progress is possible using radiolucent carbon fiber and PEEK implants, such evaluations are limited when using radiopaque, or titanium, implants (given the artifacts produced by the titanium). ${ }^{9}$ Diedrich et al. have indicated that with MRI analysis, it is possible to differentiate between atrophic tissue and bony fusion within PEEK and carbon fiber cages, while such differentiation is impossible within metal cages..$^{14}$

Mechanical properties of the interbody implants should also be considered when implanting interbody devices.

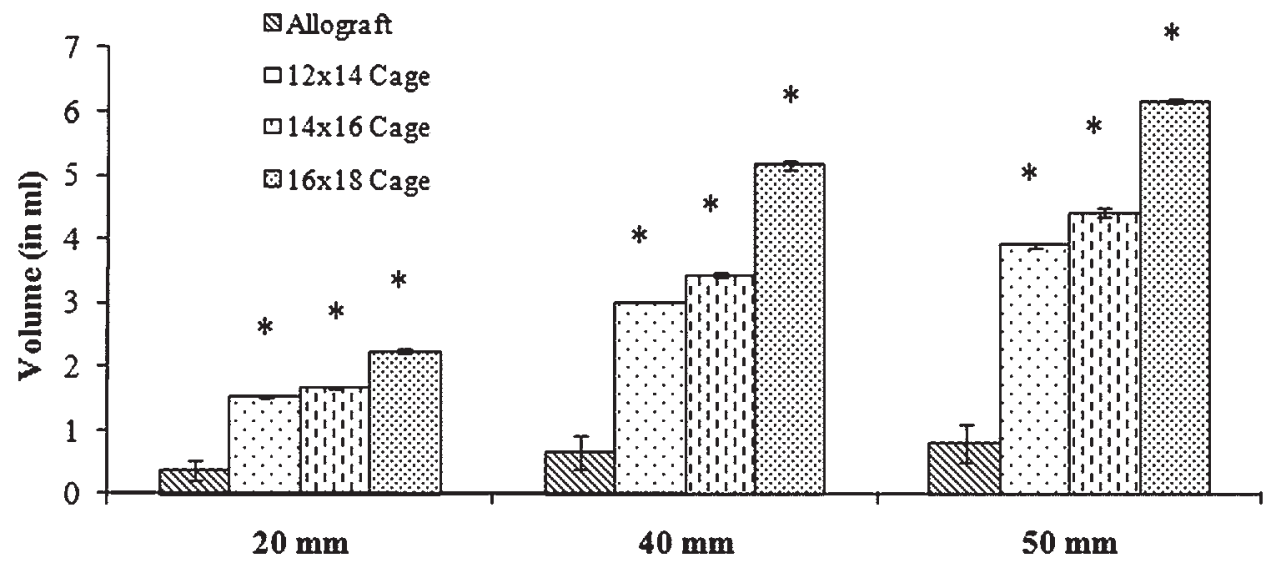

FIG. 4. Comparison of volume of olive oil that can be placed into 6 fibular allografts and 3 CFRP cages with different footprints. Asterisk indicates significant difference $(p<0.01)$, compared to allograft. $p<0.0001$ for each of the 3 sizes of cages. 


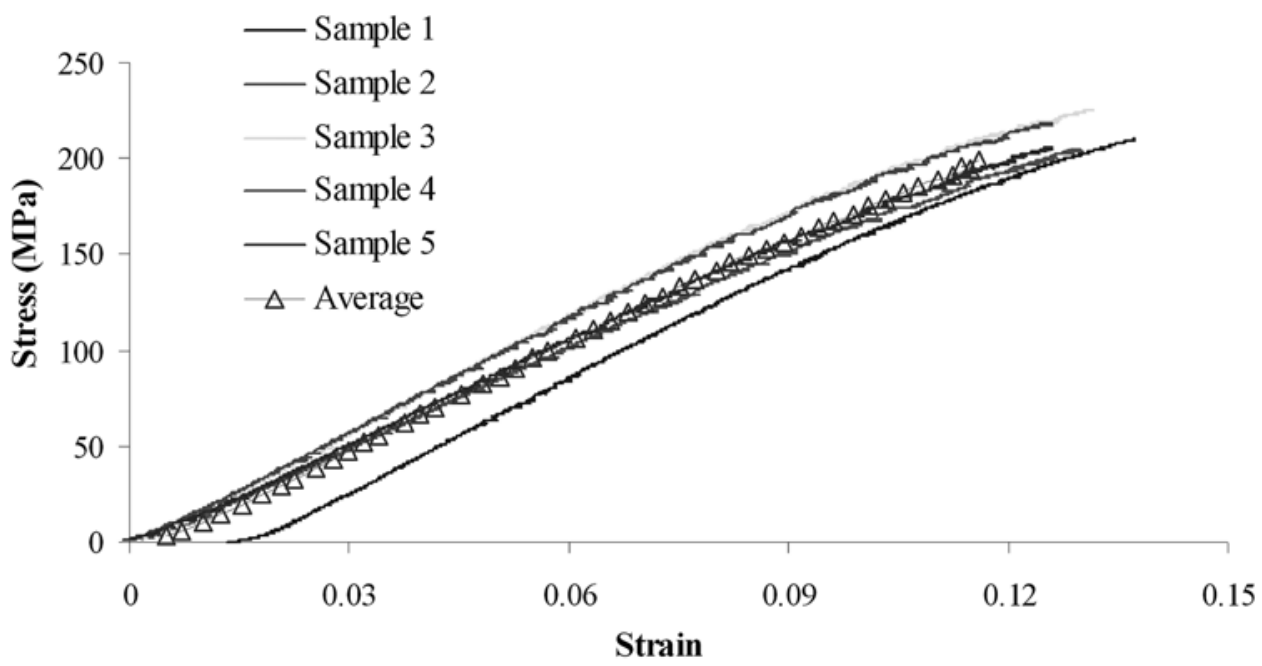

FIG. 5. Stress-strain curves for 5 CFRP cubes allowed for the calculation of Young's modulus of elasticity. Based on the load versus deformation curves, the mean modulus of elasticity for CFRP is $16.44 \pm 2.07 \mathrm{GPa}$.

In particular, analysis of Young's modulus of elasticity, a measure of the stiffness of a material, is important to ensure stability of both the implant and the spine. One of the major problems associated with metallic implants is the modulus mismatch between the fusion devices and the surrounding vertebrae. ${ }^{39}$ Cages with stiffness much

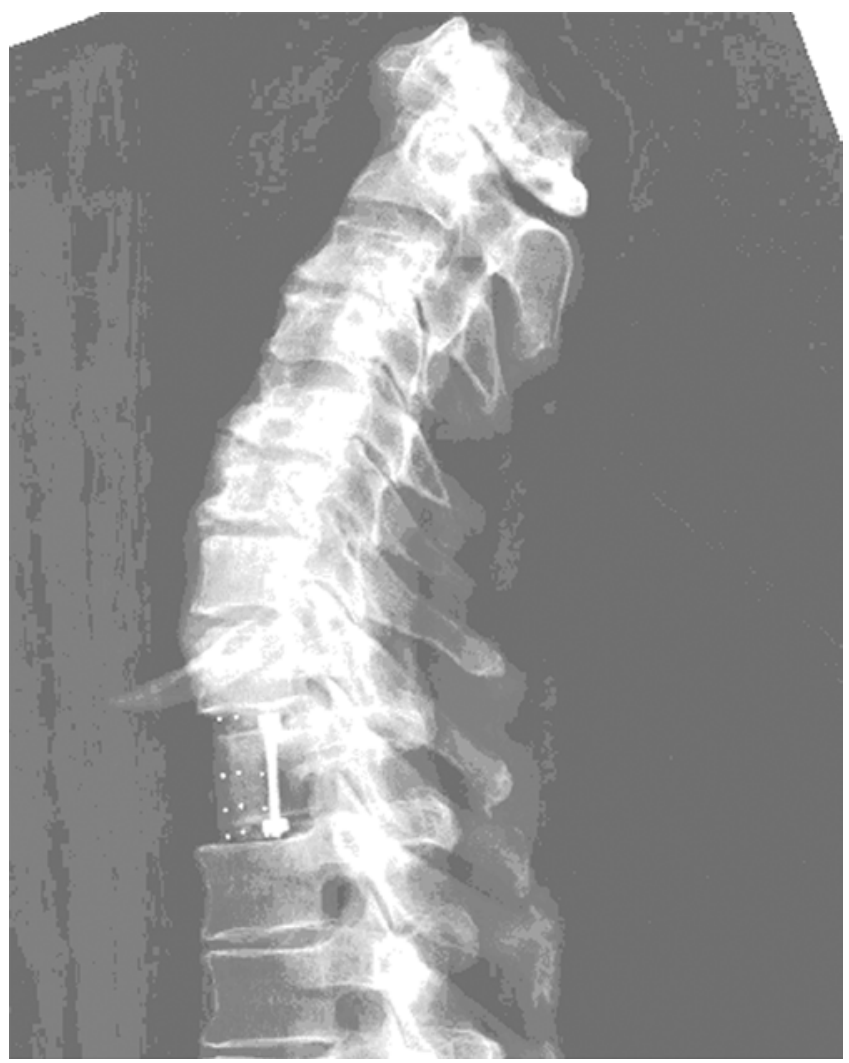

FIG. 6. Conventional radiograph, lateral view, showing CFRP cage implanted at the T-2 vertebral level. Morselized bone graft was packed into the cage prior to implantation. Radiolucency of the cage on a plain film radiograph is demonstrated. Tantalum beads embedded in the ends of the CFRP cage are visible and delineate the margins of the cage. greater than that of surrounding bone, such as cages made of titanium, have been shown to accelerate the degenerative process at adjacent levels..$^{28,47}$ Less stiff implants, such as those made of CFRP as opposed to titanium, are associated with fewer occurrences of cage subsidence, $, 15,17,48$ perhaps augmenting the recent clinical success of those constructs made from carbon fiber. ${ }^{1,8,12,34,43}$ Our results show that the modulus of elasticity for CFRP is $16.44 \pm$ $2.07 \mathrm{GPa}$. This value is much closer to the modulus values for both cortical and trabecular bone $(18.6$ and $10.4 \mathrm{GPa}$, respectively), as reported by Rho et al., ${ }^{32}$ than those for titanium and steel (110 and $210 \mathrm{GPa}$, respectively).11,16,46 This relative modulus compatibility allows for an even distribution of physiological loads to the bone graft inside the implant. . $^{37,47}$

The geometry of fusion implants is another factor when considering bony fusion through the device. In the case of allograft, bony fusion involves creeping substitution during which new bone is formed on the nonviable allograft bone. This process involves degradation of the allograft bone while the new bone is formed. The stability of the spinal section during this substitution process has been a point of concern. ${ }^{21}$ Cage designs eliminate this concern as the strength of the construct itself remains unchanged throughout the fusion process. Furthermore, the hollow and holed design of these cages allows for bony fusion growth both through and around the cage. Note that the present study does not account for the possibility of additional bony fusion around the cage. This means that the advantages may be even greater than the values reported in this study.

When it comes to evaluating interbody fusion devices, while the aforementioned factors (Young's modulus and radiolucency) have been greatly studied, the ability of a device to create a milieu that promotes bony fusion is of equal, if not greater, importance. Yet few studies have evaluated the ability of an interbody device to promote fusion. To address this issue, the primary concerns addressed in our study were the characteristics of an interbody device that allow it to promote bony fusion. We identified 2 measurable quantities, in particular, from which the ability of 


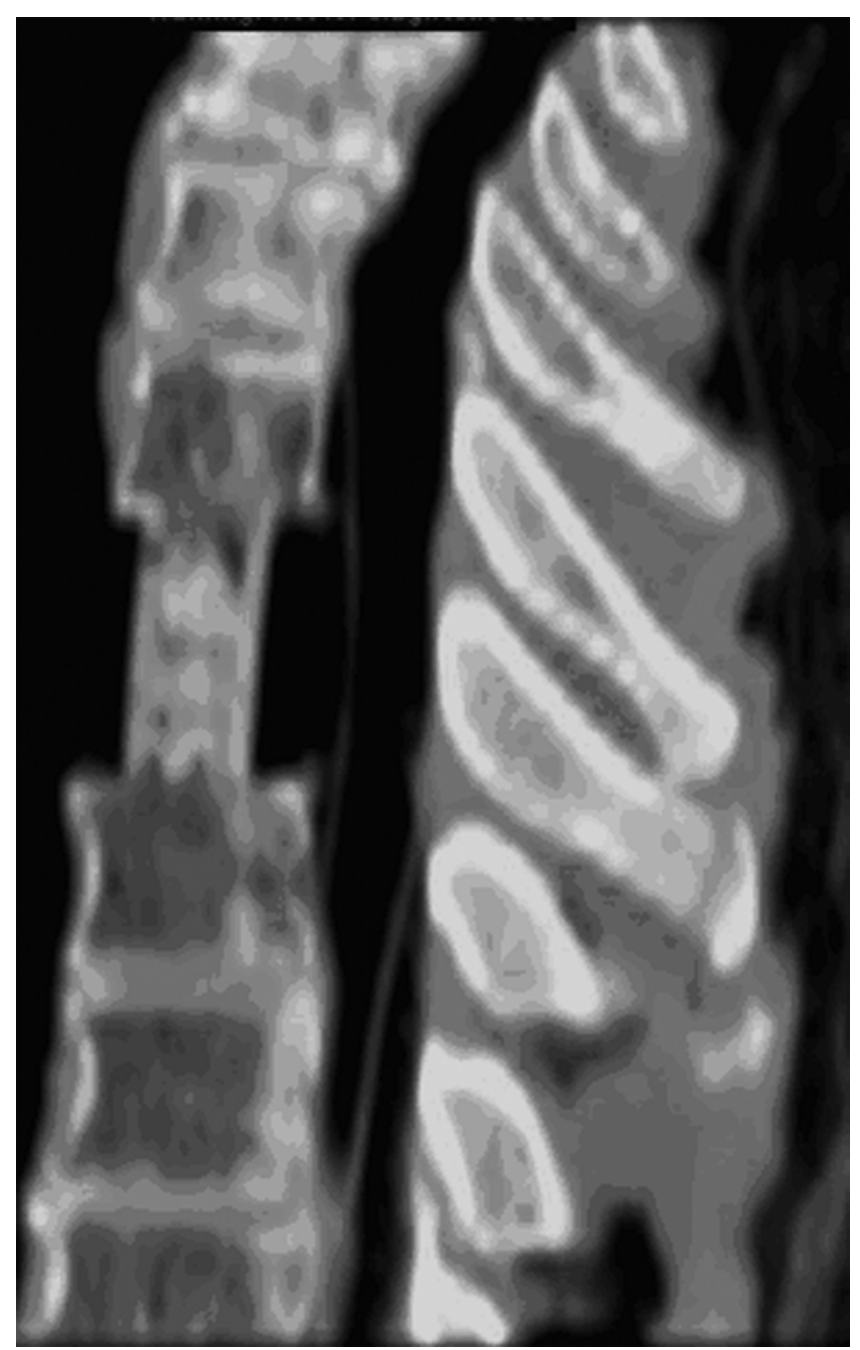

FIG. 7. Sagittal reconstructed CT scan showing CFRP cage implanted in thoracic spine at the T-2 vertebral level. Morselized bone graft was packed into the cage prior to implantation. Ability to visualize the cage on CT scanning is demonstrated.

a device to allow for bony fusion could be determined: the amount of material that could be packed in a device and the total area of interface between the fusion material and the vertebral bodies.

Multiple studies have indicated that larger amounts of fusion material (that is, autologous bone packed into interbody devices) result in greater success of fusion. . $^{1,22,23,52}$ An in vivo human study by Kim et al. has shown that $55 \%$ of the initial graft volume is lost 18 months after surgery. Therefore, the greater the initial graft volume, the larger the fusion mass at 18 months after surgery. ${ }^{23}$ Allograft packed with autologous bone material also has fusion occurring through the center of the allograft lumen (by autograft material). As shown in our study, the weight and volume of autograft material is much less $(\mathrm{p}<0.0001)$ with fibular allograft than with CFRP cages. Furthermore, far lower standard deviations for the CFRP cages indicated that the consistency of the volume packed into the CFRP implant can be maintained.

Studies have also shown that the total area of interface between autologous bone graft and vascularized vertebral body bone is an important consideration when promoting bony fusion. ${ }^{45,51} \mathrm{~A}$ study by Biederman indicates that a maximum of only $10 \%$ of the surface area of a vertebral body serves as an interface between graft and bone in Bagby and Kuslich (BAK) cages. ${ }^{51}$ Our results show that the footprint area of the CFRP cage available for fusion, which can be measured through the internal area, is significantly greater than that of the fibular allografts.

Of note, clearly the consistency of the oil is very different from any graft material. Likewise, the ability to determine the amount of graft material that can be incorporated may also be different. For instance, since oil is a liquid, it is very easy to place the maximal amount of material in the cage just by pouring. However, the volume of solid intragraft material used in clinical practice is limited by the ability of the surgeons to pack the cage or allograft. Therefore, our model may overestimate the volume available for packing and accentuate the differences between cages and allograft.

\section{Conclusions}

Our results demonstrated that carbon fiber cages can accommodate significantly $(\mathrm{p}<0.0001)$ more olive oil (both weight and volume) than can fibular allografts. We determined that the surface area available for fusion is 4-6 times more for CFRP cages than for fibular allograft samples. The modulus of elasticity of CFRP was found to be similar to cortical bone; thus, a modulus mismatch between the implant and surrounding bone is minimized. If the goal of spinal reconstruction is to achieve long-term stable fusion, then filling a CFRP cage with autograft bone will allow a 4- to 6-fold increase in the amount of bone that can be packed into the carbon fiber cages. The ability to place more graft material within cages may result in higher fusion rates in clinical practice.

\section{References}

1. Allen BL Jr, Ferguson RL: The operative treatment of myelomeningocele spinal deformity-1979. Orthop Clin North Am 10:845-862, 1979

2. Armitage P, Berry G, Matthews JNS: Statistical Methods in Medical Research, ed 4. Malden, MA: Blackwell Science, 2002

3. Aryan HE, Lu DC, Acosta FL Jr, Ames CP: Corpectomy followed by the placement of instrumentation with titanium cages and recombinant human bone morphogenetic protein-2 for vertebral osteomyelitis. J Neurosurg Spine 6:23-30, 2007

4. Baskin DS, Ryan P, Sonntag V, Westmark R, Widmayer MA: A prospective, randomized, controlled cervical fusion study using recombinant human bone morphogenetic protein-2 with the CORNERSTONE-SR allograft ring and the ATLANTIS anterior cervical plate. Spine (Phila Pa 1976) 28:1219-1225, 2003

5. Bishop RC, Moore KA, Hadley MN: Anterior cervical interbody fusion using autogeneic and allogeneic bone graft substrate: a prospective comparative analysis. J Neurosurg 85:206-210, 1996

6. Bohlman HH, Eismont FJ: Surgical techniques of anterior decompression and fusion for spinal cord injuries. Clin Orthop Relat Res (154):57-67, 1981

7. Bolesta MJ, Rechtine GR II, Chrin AM: Three- and four-lev- 
el anterior cervical discectomy and fusion with plate fixation: a prospective study. Spine (Phila Pa 1976) 25:2040-2046, 2000

8. Brantigan JW, Steffee AD, Geiger JM: A carbon fiber implant to aid interbody lumbar fusion. Mechanical testing. Spine (Phila Pa 1976) 16 (6 Suppl):S277-S282, 1991

9. Brodke DS, Willie BM, Maaranen EA, Bloebaum RD: Spinal cage retrieval and assessment of biologic response. J Spinal Disord Tech 15:206-212, 2002

10. Cauthen JC, Kinard RE, Vogler JB, Jackson DE, DePaz OB, Hunter OL, et al: Outcome analysis of noninstrumented anterior cervical discectomy and interbody fusion in 348 patients. Spine (Phila Pa 1976) 23:188-192, 1998

11. Cho DY, Liau WR, Lee WY, Liu JT, Chiu CL, Sheu PC: Preliminary experience using a polyetheretherketone (PEEK) cage in the treatment of cervical disc disease. Neurosurgery 51:1343-1350, 2002

12. Ciappetta P, Boriani S, Fava GP: A carbon fiber reinforced polymer cage for vertebral body replacement: technical note. Neurosurgery 41:1203-1206, 1997

13. Deutsch H, Haid R, Rodts G Jr, Mummaneni PV: The decision-making process: allograft versus autograft. Neurosurgery 60 (1 Supp1 1):S98-S102, 2007

14. Diedrich O, Perlick L, Schmitt O, Kraft CN: Radiographic characteristics on conventional radiographs after posterior lumbar interbody fusion: comparative study between radiotranslucent and radiopaque cages. J Spinal Disord 14:522532,2001

15. Fayazi AH, Ludwig SC, Dabbah M, Bryan Butler R, Gelb DE: Preliminary results of staged anterior debridement and reconstruction using titanium mesh cages in the treatment of thoracolumbar vertebral osteomyelitis. Spine J 4:388-395, 2004

16. Fuss FK, Sabitzer RJ, Teo EC, Lee KK: Biomechanics of the spinal motor segment after fusion with a novel spacer for the minimally invasive extraforaminal approach. Presented at the ICBME 2002 Conference, Singapore (http://www.ntu.edu. sg/home/mecteo/Conference/CP_21FP.pdf ) [Accessed February 19, 2016]

17. Gercek E, Arlet V, Delisle J, Marchesi D: Subsidence of stand-alone cervical cages in anterior interbody fusion: warning. Eur Spine J 12:513-516, 2003

18. Graham JJ: Complications of cervical spine surgery. A fiveyear report on a survey of the membership of the Cervical Spine Research Society by the Morbidity and Mortality Committee. Spine (Phila Pa 1976) 14:1046-1050, 1989

19. Heary RF, Schlenk RP, Sacchieri TA, Barone D, Brotea C: Persistent iliac crest donor site pain: independent outcome assessment. Neurosurgery 50:510-517, 2002

20. Hee HT, Majd ME, Holt RT, Whitecloud TS III, Pienkowski D: Complications of multilevel cervical corpectomies and reconstruction with titanium cages and anterior plating. $\mathbf{J}$ Spinal Disord Tech 16:1-9, 2003

21. Kalfas IH: Principles of bone healing. Neurosurg Focus 10(4):E1, 2001

22. Kandziora F, Pflugmacher R, Schäfer J, Born C, Duda G, Haas NP, et al: Biomechanical comparison of cervical spine interbody fusion cages. Spine (Phila Pa 1976) 26:1850-1857, 2001

23. Kim KW, Ha KY, Moon MS, Kim YS, Kwon SY, Woo YK: Volumetric change of the graft bone after intertransverse fusion. Spine (Phila Pa 1976) 24:428-433, 1999

24. Lu DC, Wang V, Chou D: The use of allograft or autograft and expandable titanium cages for the treatment of vertebral osteomyelitis. Neurosurgery 64:122-130, 2009

25. Macdonald RL, Fehlings MG, Tator CH, Lozano A, Fleming JR, Gentili F, et al: Multilevel anterior cervical corpectomy and fibular allograft fusion for cervical myelopathy. J Neurosurg 86:990-997, 1997
26. Majd ME, Vadhva M, Holt RT: Anterior cervical reconstruction using titanium cages with anterior plating. Spine (Phila Pa 1976) 24:1604-1610, 1999

27. Malloy KM, Hilibrand AS: Autograft versus allograft in degenerative cervical disease. Clin Orthop Relat Res (394):27-38, 2002

28. Matge G: Anterior interbody fusion with the BAK-cage in cervical spondylosis. Acta Neurochir (Wien) 140:1-8, 1998

29. McConda DB, Emery SE: Delayed fracture of fibular strut allograft following three-level anterior cervical corpectomy and fusion: a case report. W V Med J 111:14-16, 2015

30. Osebold WR, Mayfield JK, Winter RB, Moe JH: Surgical treatment of paralytic scoliosis associated with myelomeningocele. J Bone Joint Surg Am 64:841-856, 1982

31. Pollock R, Alcelik I, Bhatia C, Chuter G, Lingutla K, Budithi $\mathrm{C}$, et al: Donor site morbidity following iliac crest bone harvesting for cervical fusion: a comparison between minimally invasive and open techniques. Eur Spine J 17:845-852, 2008

32. Rho JY, Ashman RB, Turner CH: Young's modulus of trabecular and cortical bone material: ultrasonic and microtensile measurements. J Biomech 26:111-119, 1993

33. Rieger A, Holz C, Marx T, Sanchin L, Menzel M: Vertebral autograft used as bone transplant for anterior cervical corpectomy: technical note. Neurosurgery 52:449-454, 2003

34. Salame K, Ouaknine GE, Razon N, Rochkind S: The use of carbon fiber cages in anterior cervical interbody fusion: report of 100 cases. Neurosurg Focus 12(1):E1, 2002

35. Samartzis D, Shen FH, Goldberg EJ, An HS: Is autograft the gold standard in achieving radiographic fusion in one-level anterior cervical discectomy and fusion with rigid anterior plate fixation? Spine (Phila Pa 1976) 30:1756-1761, 2005

36. Senter HJ, Kortyna R, Kemp WR: Anterior cervical discectomy with hydroxylapatite fusion. Neurosurgery 25:39-43, 1989

37. Shono Y, McAfee PC, Cunningham BW, Brantigan JW: A biomechanical analysis of decompression and reconstruction methods in the cervical spine. Emphasis on a carbon-fibercomposite cage. J Bone Joint Surg Am 75:1674-1684, 1993

38. Silber JS, Anderson DG, Daffner SD, Brislin BT, Leland JM, Hilibrand AS, et al: Donor site morbidity after anterior iliac crest bone harvest for single-level anterior cervical discectomy and fusion. Spine (Phila Pa 1976) 28:134-139, 2003

39. Sohn MJ, Kayanja MM, Kilinçer C, Ferrara LA, Benzel EC: Biomechanical evaluation of the ventral and lateral surface shear strain distributions in central compared with dorsolateral placement of cages for lumbar interbody fusion. J Neurosurg Spine 4:219-224, 2006

40. Stabler CL, Eismont FJ, Brown MD, Green BA, Malinin TI: Failure of posterior cervical fusions using cadaveric bone graft in children. J Bone Joint Surg Am 67:371-375, 1985

41. Stevenson S, Emery SE, Goldberg VM: Factors affecting bone graft incorporation. Clin Orthop Relat Res (324):6674, 1996

42. Swank ML, Lowery GL, Bhat AL, McDonough RF: Anterior cervical allograft arthrodesis and instrumentation: multilevel interbody grafting or strut graft reconstruction. Eur Spine J 6:138-143, 1997

43. Tancredi A, Agrillo A, Delfini R, Fiume D, Frati A, Rinaldi A: Use of carbon fiber cages for treatment of cervical myeloradiculopathies. Surg Neurol 61:221-226, 2004

44. Tempel ZJ, Bost JW, Norwig JA, Maroon JC: Significance of T2 hyperintensity on magnetic resonance imaging after cervical cord injury and return to play in professional athletes. Neurosurgery 77:23-31, 2015

45. Thalgott JS, Xiongsheng C, Giuffre JM: Single stage anterior cervical reconstruction with titanium mesh cages, local bone graft, and anterior plating. Spine J 3:294-300, 2003

46. Vadapalli S, Sairyo K, Goel VK, Robon M, Biyani A, Khandha A, et al: Biomechanical rationale for using polyetherether- 
ketone (PEEK) spacers for lumbar interbody fusion-A finite element study. Spine (Phila Pa 1976) 31:E992-E998, 2006

47. van Dijk M, Smit TH, Arnoe MF, Burger EH, Wuisman PI: The use of poly-L-lactic acid in lumbar interbody cages: design and biomechanical evaluation in vitro. Eur Spine J 12:34-40, 2003

48. van Jonbergen HP, Spruit M, Anderson PG, Pavlov PW: Anterior cervical interbody fusion with a titanium box cage: early radiological assessment of fusion and subsidence. Spine J 5:645-649, 2005

49. Wang JC, Hart RA, Emery SE, Bohlman HH: Graft migration or displacement after multilevel cervical corpectomy and strut grafting. Spine (Phila Pa 1976) 28:1016-1022, 2003

50. Watters WC III, Levinthal R: Anterior cervical discectomy with and without fusion. Results, complications, and longterm follow-up. Spine (Phila Pa 1976) 19:2343-2347, 1994

51. Weiner BK, Fraser RD: Spine update lumbar interbody cages. Spine (Phila Pa 1976) 23:634-640, 1998

52. Xue Q, Li H, Zou X, Bünger M, Egund N, Lind M, et al: The influence of alendronate treatment and bone graft volume on posterior lateral spine fusion in a porcine model. Spine (Phila Pa 1976) 30:1116-1121, 2005

53. Zdeblick TA, Ducker TB: The use of freeze-dried allograft bone for anterior cervical fusions. Spine (Phila Pa 1976) 16:726-729, 1991

\section{Disclosures}

Dr. Heary has been the recipient of research support and royalties from DePuy Spine for the Bengal device. No other authors have disclosures or potential conflicts of interest. All testing was performed with strict adherence to the highest ethical standards, and the authors believe that industry funding has had no effect on the results or interpretation of the results presented in this paper.

\section{Author Contributions}

Conception and design: Heary, Parvathreddy. Acquisition of data: Heary, Parvathreddy, Qayumi, Ali. Analysis and interpretation of data: all authors. Drafting the article: Heary, Parvathreddy, Agarwal. Critically revising the article: Heary, Parvathreddy, Agarwal. Reviewed submitted version of manuscript: all authors. Statistical analysis: Heary, Parvathreddy. Administrative/technical/material support: Heary. Study supervision: Heary.

\section{Correspondence}

Robert F. Heary, Department of Neurological Surgery, Spine Biomechanics Laboratory, 90 Bergen St., Ste. 8100, Newark, NJ 07101-1709. email: heary@njms.rutgers.edu. 